\section{Specialist services offer cost-effective treatment for anorexia nervosa}

Anorexia nervosa is a potentially
life-threatening eating disorder
which appears to be increasing
in children, although this
could mean that services are
getting better at identifying
the condition. Sarah Byford,
Professor of Health Economics
at King's College London, led
a team that surveyed children
and young people who were
diagnosed with anorexia nervosa
in 2015. They discovered that
specialist eating disorders
services, rather than generic
mental health services, are likely
to be the most cost-effective
treatment option. Prioritising
these services could allow more
young patients with anorexia
nervosa to receive the best
available treatment.

norexia nervosa means more $\quad$ loss, may be obvious. Other symptoms,
than simply being underweight: $\begin{array}{ll}\text { than simply being underweight; } & \text { particularly the psychological effects of } \\ \text { it is a serious, potentially life- } & \text { the illness, are far subtler. Long-term, }\end{array}$ threatening eating disorder and mental anorexia nervosa can lead to muscle health condition. Those who live with weakness, fertility issues, a weakened weight as low as possible by either not immune system and problems with vita eating enough, or exercising far too In children and young people, anorexia much, or both. People with anorexia nervosa can have an adverse effect nervosa often have a distorted view on growth. Tragically, the condition is of their own bodies, believing they are fat when, in reality, they are often severely underweight. It is possible for individuals to make a full recovery from anorexia nervosa. However, the treatment - which normally centres on therapy - can last for months or years.

Anorexia nervosa is more prevalent in girls than in boys and is most common diagnosed in 15-and 16 -year-olds. The Some signs, such as extreme weight

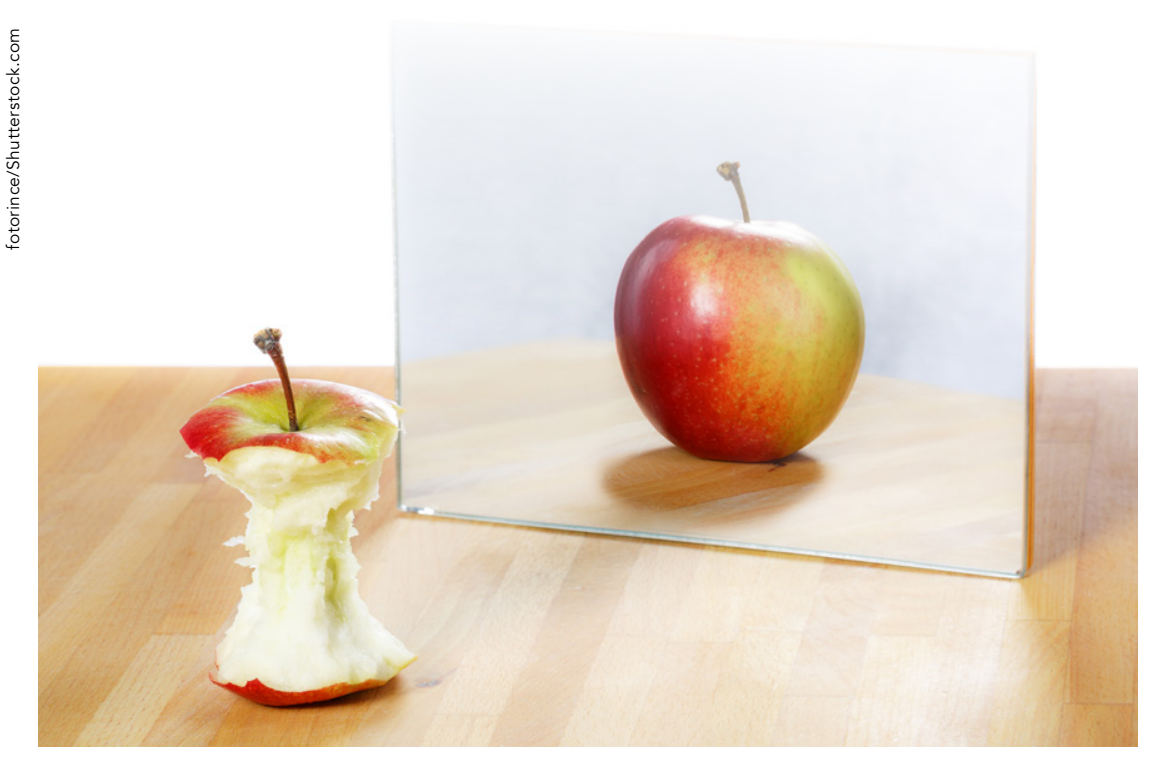

People with anorexia nervosa often have a distorted view of
when, in reality, they are often severely underweight. sometimes fatal.

THE INCIDENCE OF ANOREXIA NERVOSA Recently, Professor Sarah Byford of King's College London and her colleagues carried out a survey to identify how many young people in the UK and Ireland are diagnosed with anorexia nervosa each year (known as the incidence of anorexia nervosa). In this study, the research team used Aata collected through the Child and Adolescent Psychiatry Surveillance hospital and community psychiatrists submit monthly reports on childhood mental health conditions. The data covered an eight-month period in 2015 Doctors in the scheme were asked to submit details of any new cases of anorexia nervosa they had diagnosed during the study period. All patient data was anonymous so no individual could be identified.

The results suggest that for every 100,000 children and young people aged between eight and 17, around 14 are diagnosed with anorexia nervosa each year. Rates of anorexia nervosa in teenagers have stayed fairly stable over the last ten years. Perhaps most

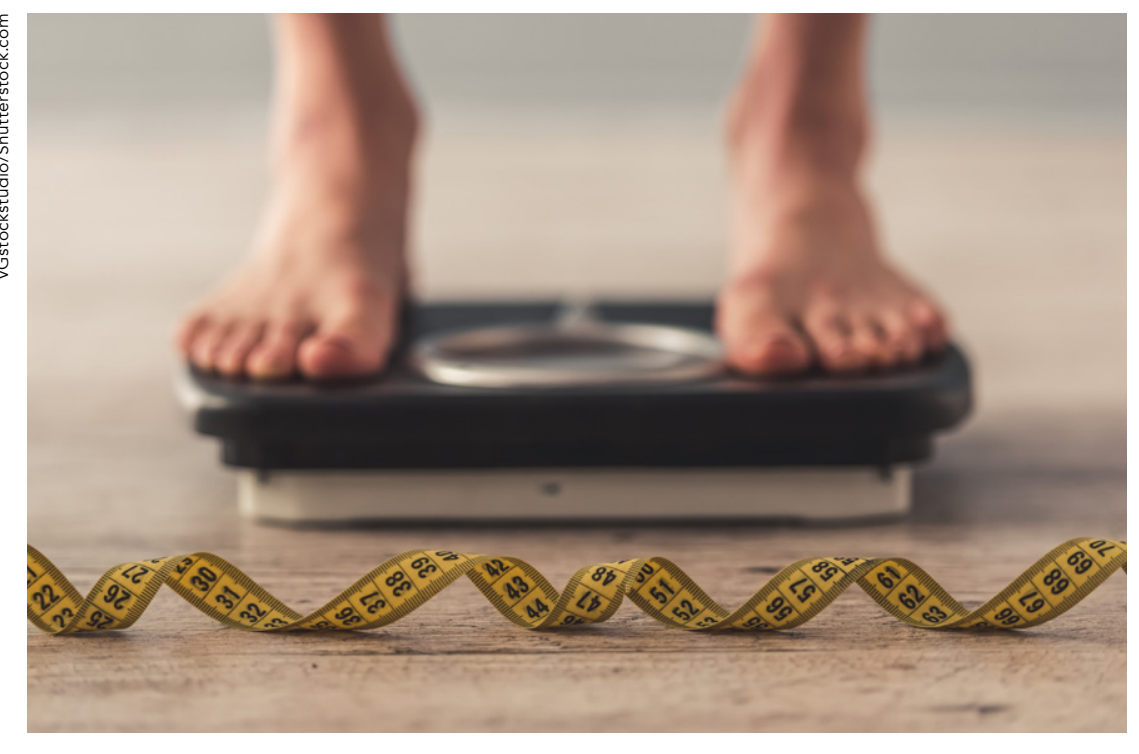

Ideally, children and young people with anorexia nervosa would be diagnosed and receive approp
treatment before their condition deteriorates to the extent that they need to be hospitalised. appears to be on the increase in children aged 12 and under. Although this could also mean that services the condition. service (if available), or to a generic child and adolescent mental health service (CAMHS).

THE COST OF ANOREXIA NERVOSA Anorexia nervosa is often a longterm, complicated condition, and young people being admitted to hospital. Sadly, some recent evidence suggests that the numbers of young people admitted to hospital for this condition are increasing and the time spent in hospital can be considerable. This means that anorexia nervosa is an expensive condition to treat. In have a negative impact on a patient's family, social and school life. There is, therefore, a need to identify the best ways to keep young people out of hospital.

TWO ROUTES TO EATING DISORDER TREATMENT Ideally, children and young people with anorexia nervosa would be diagnosed and receive appropriate treatment before their condition deteriorates to the extent that they need to be hospitalised. Individuals affected by anorexia nervosa may try a range of their peth to recosy and services on their path to recovery. If a GP in the UK or the Republic of Ireland believes that
a child may be experiencing an eating While either of these pathways amount of evidence to suggest that the life-threatening nature of the condition unfortunately leads to many disorder, they will commonly refer them

there has been little research on the disorders services versis CAMHS. addition, we do not know which service is better at keeping young people out of hospital and which is the most costeffective (the best value for money). This information would help the NHS to ensure that scarce resources are spent on those services that are of most benefit to patients.

To address this problem, Professor Byford and her colleagues used their survey of young people with anorexia nervosa to collect information on the costs and benefits of the two treatment routes. In this in-depth research, the team aimed to reveal the relative costeflectiveness of CAMHS and Some previous research had shown specialist senvices can be more costeffective than both inpatient hospita treatment and CAMHS. However this research is dated, and healthcare provision has changed since it was conducted. Professor Byford and her team hoped to find out if specialist services really are cost-effective compared to CAMHS in the UK and be the meating disorders senices

Ireland today.

Anorexia nervosa means more than simply being underweight; it is a serious, potentially life-threatening eating disorder and mental health condition.

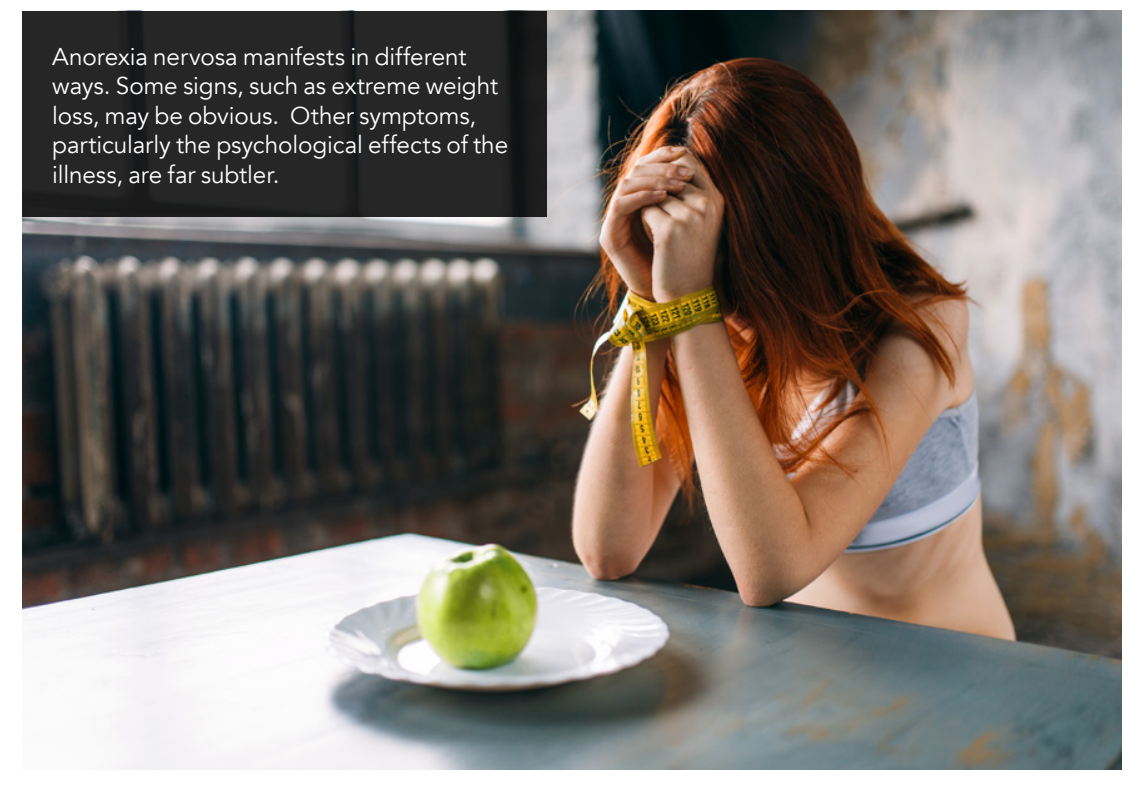


HOW WAS THE RESEARCH

Poria nervosa Professor Byford and her colleagues doctors were asked to provide details of the young people and their outcomes. These details included age, gender, ethnicity and body mass index, as we as a Children's Global Assessment scale (CGAS) score. Doctors use the CGAS to assess a child's emotiona and behavioural health, in a family, social and school context. Used in this way, the CGAS can help to create an impression of the overall impact of an eating disorder on a young person's Iffe. In addition, the team estimated the treatment costs of each case for period of 12-months after the young people were dagnsed. These costs for the various services each young person used.

In total, the team were able to collect data on 298 new cases of anorexia nervosa diagnosed within the eightmonth window. All patients were aged between 8 and 17 years. The majority $64 \%$ ) of these patients were seen in a specialist eating disorders service, while the remaining $36 \%$ were assessed in generic CAMHS.

\section{ARE SPECIALIST SERVICES}

MORE EFFECTIVE?

The data submitted by doctors showed that young people referred to special diunosis, compered to unut at dichosis this, patients treated by specialist services seem to improve more quicklyThe team found that those young people in specialist senvices have significantly better weight gain at six months after initial diagnosis, compared to young people in CAMHS. By 12 months, the outcomes were roughly equal for both services. However, the treatment costs of young people in the specialist services are lower, meaning that this treatment route may be more

ARE SPECIALIST SERVICES COST- EFFECTIVE?

The results demonstrated that, for

children and young people, specialist

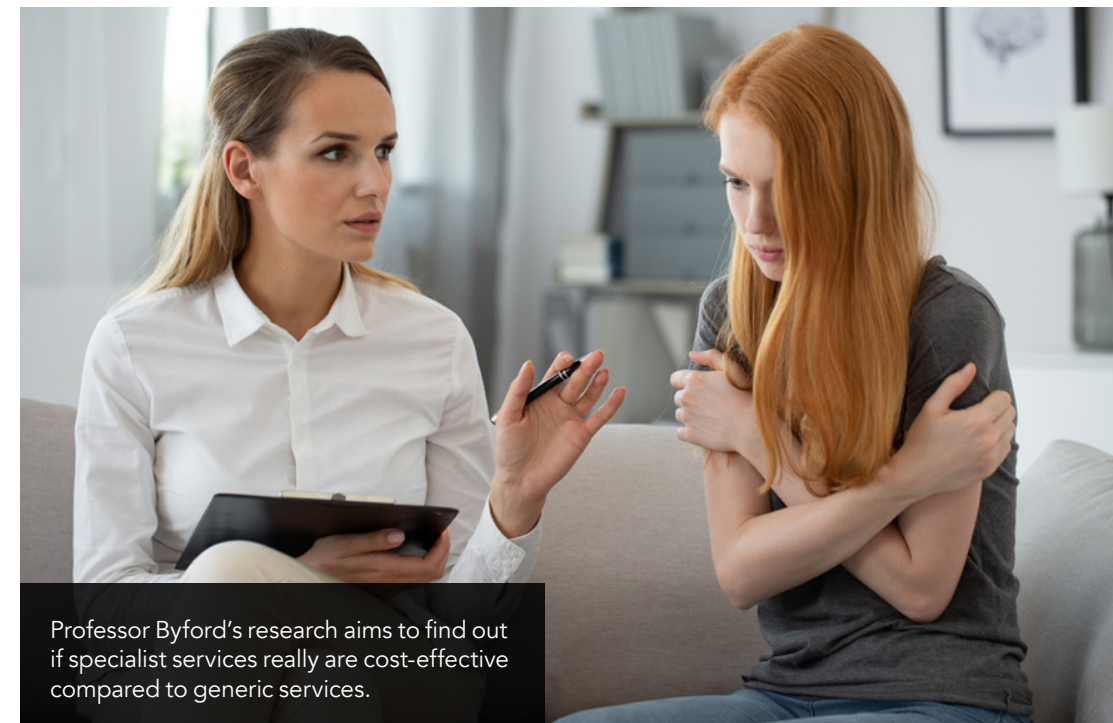

Professor Byford and her colleagues have identified specialist services as the most cost-effective treatment route for anorexia nervosa patients.

services are at least as cost-effective than generic CAMHS. Interestingly, the are free to patients. At the individual level, improving health and overall may actually be more cost-effective quality of life is the most important man and however, the work of Professor idea of "willingness to pay." At low levels of willingness to pay - that is, when society is reluctant to invest in these services - specialist services At higher leve of willingetive. At higher levels of willingness to pay equally likely to be cost-effective.

The results achieved by Professor Byford and her colleagues support those of older studies, which found that specialst outpatient treatment is more likely to be cost-effective than either inpatient or general outpatient treatment in CAMHS. There is also some evidence that young people receiving treatment from a specialist service are significan less likely to need hospital admission, compared to those being treated by non-specialist service.

From the point of view of an individual patient and their family, cost-

influence their treatment - at least, not in hopes that future research will examine the long-term costs and benefits of to follow children and young people into a healthy adulthood.

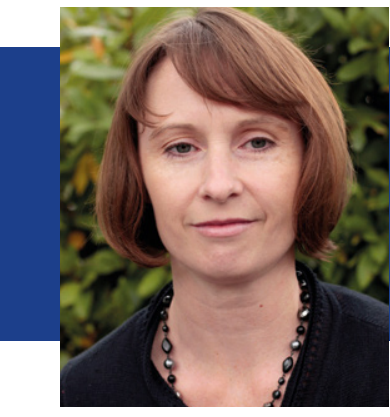

\section{Behind the Research} Professor Sarah Byford

\section{Research Objectives}

Sarah Byford leads a team of health economists with xpertise in designing and conducting high quality ecoro

\section{Detai}

Professor Sarah Byford

lation Research Department P024 David Goldberg Centre

Astitute of Psychiatry, Psychology \& Neuroscience,

King's College London,

De Crespigny Park,
London SE5 8AF

Sarah Byford is Professor of Health Economics at the Institute of Psychiatry Psychology \& Neuroscience, King's College London. Professor Byford specialises in the economic evaluation of mental health and social care services and has a particular interest in the evaluation of services for children and dolescents, including eating disorders services.

Funding

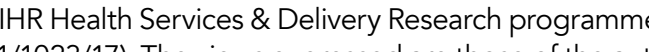
and not necessarily those of the NIHR or the Department of Health and Social Care.

Collaborators

Authors of the CostED study: Sarah Byford, Hristina Petkova, Ruth Stuart, Dasha Nicholls, Mima Simic, Tamsin Ford, Gardine Macdonald, Sin Kelly, Grace Kelly, Nuets, Livingstone, Kandarp Johi, Hen Smith and Ivan Ei. - The CostED study was carried out at the Institute of Psychiatry, Psychology \& Neuroscience at King's College London and Queen's University Belfast and supported by researchers and child and adolescent psychiatrists at Great Ormond Street Institute of Child Health, Imperial College London, NHS Grampian, NHS Greater Glasgow and Clyde, University of Abersen, University of Bristol, University of Maudsley NHS Foundation Trust.

-The Child and Adolescent Psychiatry Surveillance System, based at the Royal College of Psychiatrist's Centre for Care Quality and Improvem

We would like to thank all the clinicians who were kind enough to give up their time to provide the CostED study with CAPSS notifications and to complete questionnaires

\section{References}

Byford, S, et al. 2019; Alternative community-based models of care for young people with anorexia nervosa: the CostED Research 7(37). doi:10.3310/hsdr07370

Petkova, H, et al. 2019. Incidence of anorexia nervos in young people in the UK and Ireland: a national surveillance study. BMJ Open 9:0027339. doi:10.1136/
bmjopen-2018-027339 bmjopen-2018-027339

\section{Personal Response}

Do you think that these findings could also apply to the treatment of adult anorexia patients?

II We won't know for sure without further research but, yes, it is possible that specialist services are more costeffective for adults as well. In fact, recent guidance for adults with eating disorders of services recommends that to community eating disorders services that can provide good quality evidence-based treatments If these services are able to better improve the health and quality of life of adults with eating disorders, and keep them out of hospital
then they are likely to be cost-effective.

\section{KING'S LONDON \\ LONDON}

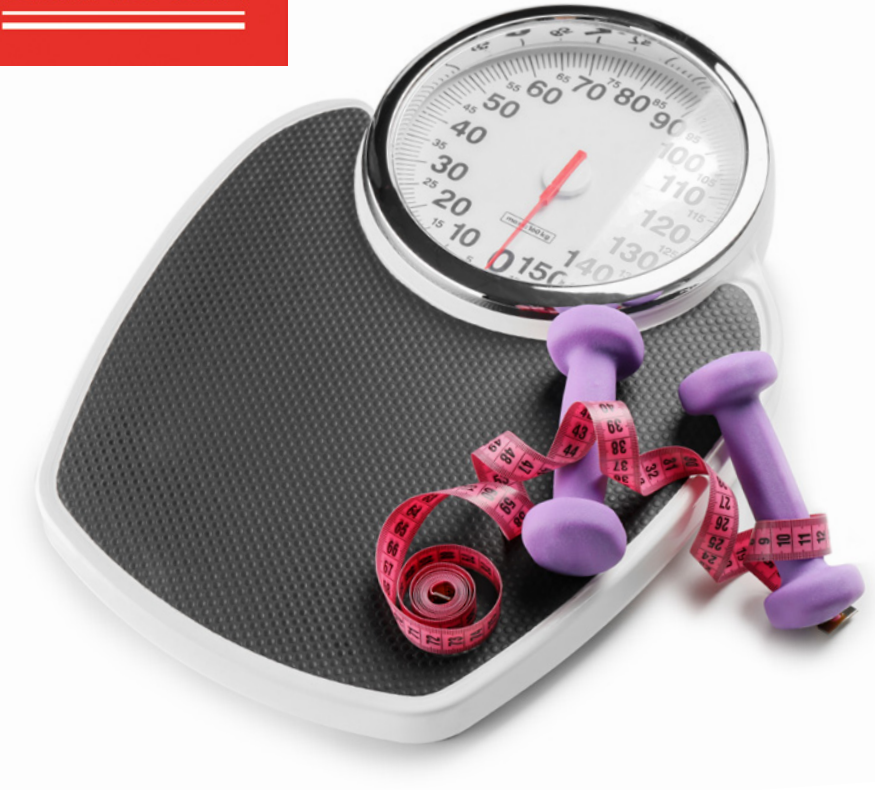

